Revista de Economia Política, vol. 28, $n^{\circ} 3$ (111), pp. 471-489, julho-setembro/2008

\title{
Matemática agradável
}

GERSON LIMA*

Pleasant Mathematics. This paper suggests a reconsideration of the principle that public deficits should be financed by public debt. Two main reasons are offered. First, it is admitted that public debt is an economic variable whose time behaviour is better described by a first difference equation instead of an accounting identity. The convergence condition thus obtained requires either a nominal negative interest rate or that government bonds are used to raise tax income, hypotheses not theoretically granted. As a consequence, if primary surplus is not sufficient to match interests' payment, it will be observed an explosive trend in the public debt, the due interests and the money issuing. Therefore, it lacks support to the idea that public debt prevents inflation. Second, it is shown that financing public deficit through money issuing leads to a stable equilibrium money stock. The general conclusion is that, in order to simultaneously promote economic growth and inflation control, money issuing is preferable to public debt.

Keywords: public debt, monetary policy, money issuing.

JEL Classification: E5; E6.

\section{INTRODUÇÃO}

Este artigo apresenta uma avaliação das duas principais formas de financiamento do déficit fiscal - a colocação de títulos da dívida pública no mercado financeiro e a emissão de moeda. Em primeiro lugar, analisa-se o endividamento público a partir do argumento econômico de que é teoricamente insuficiente descrever sua evolução temporal por meio de uma identidade contábil. Como qual-

\footnotetext{
*Professor de Teoria e Política Econômica da FACINTER - Faculdade Internacional de Curitiba, e-mail: gerson@macroambiente.com.br. Submetido: Maio 2006; Aceito: Março 2007. Os comentários críticos do Prof. Marcio Domenici Alves Segundo foram fundamentais para a elaboração deste trabalho. O autor agradece a dois pareceristas desta revista que mostraram e permitiram retificar importantes imprecisões e inconsistências em uma versão anterior do artigo.
} 
quer outra, a dívida pública é uma variável estoque que, a cada momento, resulta da acumulação da diferença entre fluxos passados de gastos e receitas. Por isso, o comportamento da dívida pública no tempo deve ser descrito por uma equação de diferenças finitas.

Resolvendo-se esta equação, chega-se à conclusão de que a condição de convergência da dívida pública ao seu ponto de equilíbrio estável exige, hipoteticamente, ou que a taxa de juros nominal seja negativa, ou que os recursos financeiros captados em títulos públicos sejam investidos de forma a gerar um aumento da arrecadação tributária suficiente para pagar os respectivos juros. Como estas duas hipóteses não têm suporte teórico, há fundamento para admitir-se que a dívida pública siga uma trajetória explosiva.

A importância teórica e prática deste fenômeno de natureza matemática é considerável. Por exemplo, ao elaborar um orçamento prevendo um superávit primário insuficiente para o pagamento dos juros da dívida pública, o governo gera, matematicamente, um processo explosivo tanto da própria dívida pública quanto do gasto com juros e da emissão de moeda. Não há, portanto, garantias de que o saldo da dívida pública e o estoque de moeda possam encontrar níveis de equilíbrio estáveis e, por conseqüência, não há meios de se assegurar que, ceteris paribus, o endividamento público permita controlar a inflação.

Em segundo lugar, e este é o objetivo maior do artigo, demonstra-se que a emissão de moeda associada ao déficit público segue um processo convergente em direção a uma situação de equilíbrio estável. Isto significa que o governo pode emitir moeda para financiar o déficit fiscal sem causar uma inflação elevada ou descontrolada. O que ocorre é que, após uma expansão deficitária do gasto fiscal, o crescimento do PIB causa um aumento de receita tributária tal que o fluxo de moeda emitida reduz-se paulatinamente até zerar. Neste momento, o estoque de moeda terá chegado ao seu ponto de equilíbrio estável. O controle do orçamento, tanto pelo poder Executivo quanto pelo Legislativo, fará então com que a inflação também esteja sob controle e seja convergente a um nível planejado de equilíbrio estável.

O texto está organizado em duas grandes seções. Na primeira avalia-se o modelo apresentado por Sargent \& Wallace para a estabilidade da dívida pública e, em seguida, adiciona-se a possibilidade de que a receita tributária esteja correlacionada com a dívida pública. A conclusão desta parte é a não rejeição da possibilidade de que qualquer modelo de endividamento público seja teoricamente inconsistente.

$\mathrm{Na}$ segunda seção desenvolve-se a análise da monetização do déficit público. Mostra-se que, para o estoque de moeda convergir em direção a um ponto de equilíbrio estável, a condição é a de que o gasto fiscal esteja não negativamente associado à receita tributária. Considerando então que não há motivo para se supor que esta associação não prevaleça na prática, mesmo na situação de pleno emprego, conclui-se que o estoque de moeda pode convergir a um valor de equilíbrio estável. Ao final apresentam-se algumas breves conclusões. 


\section{O FINANCIAMENTO DO DÉFICIT PÚBLICO}

O gasto total do governo, composto do gasto fiscal e do gasto com juros, pode ser financiado pela receita tributária, por dívida lastreada em títulos públicos ou ainda pela emissão de moeda. Este princípio pode ser expresso pela seguinte identidade contábil:

$$
\mathrm{GF}+\mathrm{GJ}=\mathrm{T}+\left(\mathrm{D}-\mathrm{D}_{-1}\right)+\left(\mathrm{M}-\mathrm{M}_{-1}\right)
$$

onde GF é o gasto fiscal durante um período de tempo qualquer e GJ é o gasto com os juros da dívida pública neste período. Do outro lado, T é a receita tributária do governo neste período, $\mathrm{D}$ é a dívida pública interna no final deste período, $\mathrm{D}_{-1}$ é esta mesma dívida no final do período equivalente imediatamente anterior, $\mathrm{M}$ é o saldo da base monetária no final do período e $\mathrm{M}_{-1}$ é o saldo desta base no final do período precedente. $\left(\mathrm{D}-\mathrm{D}_{-1}\right)$ mede então a emissão de títulos da dívida pública, enquanto $\left(\mathrm{M}-\mathrm{M}_{-1}\right)$ mede a emissão de base monetária. Nesta notação, o subscrito $\mathrm{t}$, indicativo do período de tempo, foi omitido.

O gasto fiscal GF é uma variável autônoma, no sentido de que o governo fixa seu valor de modo independente do nível de atividade da economia. Por sua vez, o gasto com juros GJ é uma conseqüência do montante da dívida pública e da taxa de juros relevante. A taxa de juros pode estar relacionada à dívida pública, seja por ser fixada pelo Banco Central, assim obrigando o governo a tomar empréstimos para garantir a taxa mínima de juros, seja por ser uma conseqüência da política monetária de enxugar liquidez por meio da colocação de títulos da dívida pública no mercado aberto. Mas, a taxa de juros pode também ser determinada livremente no mercado de capital financeiro, sendo neste caso uma variável endógena. Por sua vez, a receita tributária T é uma variável endógena, cujo valor final depende não só das alíquotas dos tributos, mas também do nível de atividade da economia.

Nas modelagens usuais do endividamento público, ${ }^{1}$ esta notação básica pode ser alterada, sendo as variáveis normalizadas pelo PIB e medidas em termos constantes, ou assim transformadas no desenvolvimento matemático do problema. ${ }^{2}$ Com relação aos pressupostos, nestes modelos a economia está em pleno emprego. Além disso, o PIB e sua taxa de crescimento são variáveis exógenas e, portanto, independentes do gasto fiscal, da dívida pública e do estoque de moeda.

Do mesmo modo, a receita tributária é uma variável exógena, podendo ser determinada pelo governo, que aparentemente fixaria qualquer nível da carga

\footnotetext{
${ }^{1}$ Estes comentários baseiam-se principalmente na leitura de Rossi (1987), Dornbusch \& Fischer (1990, pp. 614-5 e 627-8), Pastore (1995), em versão preliminar de dezembro de 1993, Giambiagi \& Além (1999, pp. 162-72) e Martone (2000, pp. 374-8).

${ }^{2}$ Por esta razão, dependendo do contexto, a dívida pública é tratada neste artigo tanto em valores absolutos como pelo seu valor relativo ao PIB, o que pode eventualmente causar algum desconforto na leitura.
} 
tributária para obter a receita desejada, também independentemente do montante da dívida pública. O pressuposto maior é o de que a dívida pública não é afetada pela política monetária, assumindo-se que todo o endividamento decorre apenas do déficit fiscal. Ou seja, apesar da política monetária admitir taxa de juros acima do nível de mercado ou controle do estoque de moeda por meio da colocação de títulos da dívida pública, supõe-se que ela não implica endividamento público.

A principal questão que se coloca neste tema é a da evolução da dívida pública pois, ainda que estas premissas fossem realistas, a taxa de juros, mesmo que constante, pode causar o aumento do gasto com juros e, conseqüentemente, o crescimento da própria dívida, num processo infinito de realimentação.

\section{O método Sargent \& Wallace}

Dadas estas premissas, a formalização pioneira do problema é a "matemática desagradável” de Sargent \& Wallace, ${ }^{3}$ que pode ser assim expressa: ${ }^{4}$

$$
\left.\left(\mathrm{D}-\mathrm{D}_{-1}\right) / \mathrm{Y}=\mathrm{r}(\mathrm{D} / \mathrm{Y})-(\mathrm{T}-\mathrm{GF}) / \mathrm{Y}-\mathrm{dM} / \mathrm{Y}\right)
$$

onde Y é o PIB nominal, $\mathrm{r}$ é a taxa de juros nominal relevante para a dívida pública, ( $\mathrm{T}-\mathrm{GF}$ ) é o superávit primário nominal e dM mede a emissão de moeda $\left(\mathrm{M}-\mathrm{M}_{-1}\right)$. Esta expressão mostra que a dívida pública aumenta com os gastos do governo e decresce com a receita tributária e a emissão de moeda. Note-se que, implicitamente, o modelo admite que a dívida pública do período anterior $\mathrm{D}_{-1}$ é exógena, ou préedeterminada.

No método adotado por Sargent \& Wallace, considera-se que tanto o nível quanto a taxa de variação do PIB são exogenamente determinados. Este método permite que, no lado esquerdo desta expressão (1), a dívida pública varie entre o final do período atual (D) e o final do período anterior $\left(\mathrm{D}_{-1}\right)$, mas o PIB é o mesmo nos dois períodos. Dada esta simplificação matemática, e assumindo-se que não há emissão de moeda, calcula-se o diferencial da relação dívida/PIB (indicada por D/Y), usando-se a regra da razão entre duas variáveis. Após algumas substituições chegase à seguinte solução (Dornbusch \& Fischer, 1990, p. 628, notação alterada):

$$
\mathrm{d}(\mathrm{D} / \mathrm{Y})=-\mathrm{d}+(\mathrm{D} / \mathrm{Y})(\mathrm{i}-\mathrm{g})
$$

onde $\mathrm{d}(\mathrm{D} / \mathrm{Y})$ é o diferencial da relação dívida/PIB, d é o superávit primário dividido pelo PIB $\{(\mathrm{T}-\mathrm{GF}) / \mathrm{Y}\}$, i é a taxa de juros real e g é a taxa de variação do PIB real. Conclui-se assim que a relação dívida/PIB estará estabilizada quando

\footnotetext{
${ }^{3}$ Sargent, T. \& Wallace, N. "Some Unpleasant Monetarist Arithmetic", Federal Reserve Bank of Minnesota Quarterly Review, outono de 1981, desenvolvida aqui conforme apresentada em Dornbusch \& Fischer (1990, pp. 627-8), mas com a notação alterada.

${ }^{4}$ Adotou-se neste artigo o método de numerarem-se apenas as expressões matemáticas para as quais há referência no texto.
} 
o diferencial $\mathrm{d}(\mathrm{D} / \mathrm{Y})$ for nulo, sendo que a condição para tanto é que o superávit primário d deve ser igual a:

$$
\mathrm{d}=(\mathrm{D} / \mathrm{Y})(\mathrm{i}-\mathrm{g})
$$

Multiplicando por (Y), ou seja, medindo-se a dívida pública pelo seu saldo absoluto e não em termos de PIB, fica:

$$
\mathrm{T}-\mathrm{GF}=\mathrm{D}(\mathrm{i}-\mathrm{g})
$$

A conclusão permitida pelo modelo é a de que é necessário gerar um superávit primário $\{\mathrm{d}=(\mathrm{T}-\mathrm{GF})\}$ que não é, necessariamente, suficiente para pagar todo o gasto com juros, medido por (iD), no período. A dívida pública pode aumentar em montante dado por gD, mas a relação dívida/PIB seria mantida em equilíbrio estável já que o PIB também teria crescido à taxa g. Evidentemente, o gasto com juros e o superávit primário, nominais, seriam também maiores.

Pastore (1995) mantém a hipótese da monetização, via senhoriagem, e apresenta a seguinte solução de equilíbrio estacionário para a dívida pública como proporção do PIB (notação alterada $\left.{ }^{5}\right)$ :

$$
(\mathrm{D} / \mathrm{Y})^{*}=(\mathrm{d}+\mathrm{m}) /(\mathrm{i}-\mathrm{g})
$$

onde o asterisco refere-se a um valor de equilíbrio e $\mathrm{m}$ é a emissão de moeda (dM/Y), definida como senhoriagem. Pastore (1995, p. 5, nota de rodapé) admite a possibilidade de $(d+m)$ tornar-se uma variável de controle, ou seja, o governo poderia determinar autonomamente qualquer nível de superávit primário $\mathrm{d}$ e de monetização m, a qual poderia ser administrada em doses consideradas adequadas.

A solução encontrada por Giambiagi \& Além (1999, p. 167) para o equilíbrio da relação dívida pública/PIB admite a possibilidade da monetização, e pode ser expressa por:

$$
\mathrm{d}=\mathrm{D}(\mathrm{r}-\mathrm{y}) /(1+\mathrm{y})-\mathrm{m}
$$

onde a taxa de juros $r$ é nominal (e não a taxa real i) e y é a taxa de crescimento do PIB nominal, diferenciando-se da taxa real g. Com relação à monetização medida por $\mathrm{m}$, o texto adverte em seguida que "Obviamente, porém, na vida real, o espaço para isto é limitado pelo risco de que se verifique um processo inflacionário, em decorrência do aumento da quantidade de moeda em circulação" (p. 167).

A análise de Martone (2000, p. 375) é mais abrangente, condiciona a monetização à demanda de moeda e permite avaliar soluções alternativas para o equilíbrio da relação dívida pública/PIB. Contudo, aquele texto sugere (p. 377) que a única solução sem seqüelas é a obtenção de um superávit primário tal que, somado a uma contida senhoriagem, seja suficiente para pagar os juros da dívida.

5 Como sempre, a notação foi alterada para uniformizar o texto. 
Outras medidas, como a monetização da dívida e o confisco, são consideradas inconsistentes (p. 378), ao tempo em que se adverte que, se o superávit primário não for suficiente para pagar os juros da dívida pública, a emissão de moeda será inevitável.

Em resumo, a conclusão é que, para evitar-se que a relação dívida/PIB siga uma trajetória explosiva, é necessário gerar um superávit primário tal que, adicionado ou não a uma limitada monetização, seja suficiente para pagar os juros da dívida pública no período atual. Admite-se também que esta condição pode ser atendida se o PIB e, portanto, a receita tributária, aumentarem neste período atual em relação ao anterior, em decorrência de fatores exógenos. Em outras palavras, a condição necessária para a estabilidade da relação dívida/PIB é o déficit público atual zero.

Esta conclusão apresenta uma certa complexidade lógica para sua interpretação. De fato, o que se deduz é que a dívida pública só estará sob controle quando houver recursos fiscais, havendo ou não emissão de moeda, para o pagamento dos respectivos juros. Todavia, neste caso também não há déficit público e, portanto, não há necessidade de qualquer tipo de financiamento. Parece um simples jogo de palavras mas, no limite, partindo de uma situação na qual não existe dívida pública, a condição para que o endividamento público não seja explosivo é que não se comece a fazer dívida pública. Uma vez iniciada a dívida pública, sua estabilidade dependerá, contraditoriamente, de medidas exógenas que eliminem a necessidade de se emitir dívida pública.

Ceteris paribus, o endividamento público não cria, por si próprio, condições para o respectivo pagamento de juros. É esta a razão pela qual o método Sargent \& Wallace leva à conclusão de que a dívida pública só deixará de crescer quando forem adotadas medidas exógenas na área fiscal para que o déficit primário seja zero. Estas medidas são de natureza contábil, pois visam apenas gerar um superávit primário tal que, dada uma certa senhoriagem, supostamente sob controle do Banco Central e sem causar gastos com juros, e dado um crescimento exógeno do PIB, sejam pagos os juros da dívida pública.

\section{Endividamento, rolagem da dívida pública e emissão de moeda}

O título de matemática desagradável usado por Sargent \& Wallace talvez se deva à esperada inevitabilidade de que, se a dívida não for contida, chegará um momento em que a monetização do déficit poderá ser excessiva e, por isso, a inflação seria pior do que se, desde o início, o déficit tivesse sido financiado por emissão de moeda. "Se o governo ultrapassar seus limites de financiamento, produzirá uma tendência explosiva da dívida pública e, em última instância, uma hiperinflação" (Martone, 2000, p. 374).

A condição (3) é a solução encontrada por Sargent \& Wallace, no sentido de que, para evitar-se a inflação, é isto e exatamente isto que deve ser feito. Não sendo obtido o superávit primário requerido, a estabilidade da dívida pública exige que haja emissão de moeda $\mathrm{dM}$, em montante igual à diferença entre o quanto 
necessário para pagar os juros da dívida GJ e o superávit primário efetivamente obtido (T - GF). Em termos contábeis:

$$
\mathrm{dM}=\mathrm{GJ}-(\mathrm{T}-\mathrm{GF})
$$

Na prática, esta emissão de moeda ocorre junto com o resgate dos títulos públicos, uma operação contábil involuntária para o Banco Central que, deste modo, expande a base monetária. A política monetária de mercado aberto pode então vir a ser utilizada com o objetivo de contrair a base em parte ou totalmente, assim colocando títulos da dívida pública no mercado financeiro. Este seria o procedimento seguido quando se admite uma monetização parcial da dívida pública, sob controle da política monetária, a qual permitiria ao governo recolher senhoriagem ou imposto inflacionário para pagar parte dos juros da dívida pública e, supõe-se, não haveria hiperinflação.

O programa de metas de inflação modifica este procedimento ao fixar uma taxa de juros acima do mercado e absorver automaticamente o excesso de reservas dos bancos comerciais, a esta taxa de juros. Mas o resultado ainda pode ser o mesmo, ou seja, a troca da moeda emitida para pagar juros por novos títulos da dívida pública. Olhando-se as duas operações em conjunto - o resgate dos títulos e a colocação de novos títulos — pode parecer que houve uma rolagem da dívida pública. Trata-se, contudo, de uma rolagem especial, posto que a emissão de moeda de fato aconteceu, embora omitida do modelo.

Ou seja, apesar de ter havido emissão de moeda, poder-se-iam criar modelos de endividamento público como se isto não tivesse acontecido. O pressuposto neste caso seria o de que os bancos comerciais reteriam um estoque crescente de títulos da dívida pública, sem receber — em moeda — os juros de tal estoque de títulos. O governo receberia moeda pelos títulos que emitisse e colocasse no mercado financeiro, mas pagaria os juros destes títulos com mais títulos, títulos estes que jamais seriam convertidos em moeda. Os bancos comerciais reteriam os títulos ad eternum, sem nada receber por eles. Em outros termos, neste caso de rolagem automática da dívida pública, os bancos estariam estocando um papel inútil e doando moeda para o governo, isto é, emitindo moeda gratuitamente para o governo. Como esta situação é absurda, a rolagem automática da dívida pública também não existe como tal.

\section{O caso geral de endividamento}

Um outro método matemático e outras conclusões podem surgir se for suprimida a simplificação matemática introduzida na expressão (1), onde a dívida pública varia entre o início e o final do período, mas o PIB é constante. Indo além do modelo Sargent \& Wallace, pode-se reformular este ponto considerando que o PIB pode variar entre os dois momentos em que se observa a dívida pública. Considerando-se ainda que o fluxo de pagamento de juros no período atual decorre do estoque da dívida no final do período anterior, a expressão (1) passaria a ser: 
$(\mathrm{D} / \mathrm{Y})-(\mathrm{D} / \mathrm{Y})_{-1}=\mathrm{r}(\mathrm{D} / \mathrm{Y})_{-1}-(\mathrm{T}-\mathrm{GF}) / \mathrm{Y}-\mathrm{dM} / \mathrm{Y}$

que conduz a:

$\left.(\mathrm{D} / \mathrm{Y})-(1+\mathrm{r})(\mathrm{D} / \mathrm{Y})_{-1}=-(\mathrm{T}-\mathrm{GF}) / \mathrm{Y}-\mathrm{dM} / \mathrm{Y}\right)$

Esta é uma equação de diferenças finitas, linear, de primeira ordem, não homogênea. ${ }^{6}$ Isto ocorre porque a dívida pública ao final do período atual $(\mathrm{t})$ é consequiência dos fluxos atuais de PIB, receita tributária, gasto fiscal, gasto com juros, emissão de moeda e, importante frisar, da dívida pública precedente (t-1). Por sua vez, o PIB, a receita tributária, o gasto fiscal, o gasto com juros e a emissão de moeda anteriores são resultados de decisões que, em parte, levaram em conta a dívida pública no momento precedente ( $\mathrm{t}-2$ ). Indo mais ao passado, a história se repete eternamente, ou seja, os fluxos de hoje dependem de estoques de ontem que, por sua vez, dependem dos fluxos de antes de ontem, e assim indefinidamente.

Neste enfoque, a dívida pública do período anterior $\mathrm{D}_{-1}$ deixa de ser exógena, ou predeterminada, passando a ser uma variável endógena ${ }^{7}$ que descreve uma certa trajetória ao longo do tempo, a qual depende dos choques exógenos e dos parâmetros da equação. Por sua vez, estes parâmetros refletem o comportamento dos agentes econômicos que, em parte, levam à determinação do PIB, ou seja, aquilo que se poderia chamar de estrutura ou sistema econômico. Trata-se, portanto, de um problema de natureza econômica, situado além do que medidas contábeis podem resolver.

A solução particular da equação de diferenças finitas (5), ou seja, o ponto teórico de equilíbrio intertemporal da dívida pública, pode ser deduzido, matematicamente, quando se simula a situação na qual a dívida pública pára de variar, isto é, quando ocorre a igualdade $\left[(\mathrm{D} / \mathrm{Y})=(\mathrm{D} / \mathrm{Y})_{-1}\right]$. Substituindo-se esta igualdade hipotética na expressão (5) da dívida pública, obtém-se uma simulação da dívida pública em equilíbrio estável $\mathrm{D}^{*}$, que é dada por:

$$
\mathrm{rD}^{*}=(\mathrm{T}-\mathrm{GF}+\mathrm{dM})
$$

A solução particular de uma equação de diferenças finitas é qualquer uma que satisfaça a condição teórica de equilíbrio, ou seja, qualquer combinação dos níveis de PIB, gastos, receita tributária e emissão de moeda que satisfaça a condição (6). Imaginando-se uma solução puramente contábil, o governo escolheria, ceteris paribus o PIB, quaisquer níveis de gasto fiscal GF, receita tributária T e emissão de moeda $\mathrm{dM}$ que gerassem um valor igual ao gasto com juros $\mathrm{GJ}$ (igual a $\mathrm{r} \mathrm{D}^{*}$ ). Dada então a taxa de juros, a dívida de equilíbrio ficaria determinada.

Entretanto, o fato de se simular e calcular matematicamente uma solução de equilíbrio não quer dizer que esta solução esteja garantida no mundo real, ain-

\footnotetext{
${ }^{6} \mathrm{O}$ tratamento matemático aqui desenvolvido segue a exposição de Chiang, 1982.

${ }^{7}$ Todavia, a possível emissão de títulos da dívida pública por parte da política monetária de taxas de juros ou de controle do estoque de moeda introduz um grau de exogeneidade na dívida pública.
} 
da que se adotem medidas contábeis radicais. ${ }^{8}$ Por isso, a solução geral de uma equação de diferenças finitas exige que se deduza a sua solução complementar, ou condição de convergência, ${ }^{9}$ ou, ainda, a condição matemática para que a trajetória temporal da dívida pública seja em direção à solução de equilíbrio. Neste caso descrito pela expressão (5), esta condição é dada por:

$$
0<(1+\mathrm{r})<1
$$

ou seja, a condição de estabilidade do equilíbrio da relação dívida pública/ PIB depende da taxa de juros nominal, que deve estar no intervalo $(-1,0)$. Matematicamente, isto significa que, dada uma combinação de superávit primário com emissão de moeda que seja diferente do gasto com juros, a relação dívida/PIB só convergirá para um ponto de equilíbrio estável se a taxa de juros nominal for negativa. Em outros termos, o equilíbrio só poderia ser assegurado se, dados um superávit primário e uma emissão de moeda quaisquer, o governo pudesse fixar uma taxa de juros negativa para os títulos públicos. Assim, os bancos estariam estocando parte dos títulos da dívida pública ad eternum e inutilmente, ou seja, emitindo moeda gratuitamente para financiar o déficit público.

Dado que, normalmente, a taxa de juros é positiva, a partir de um valor de desequilíbrio a dívida pública crescerá ou diminuirá indefinidamente. Qualquer superávit primário inferior ao gasto com juros líquido da emissão de moeda implica um comportamento explosivo da relação dívida pública/PIB. ${ }^{10}$ Como acontece com qualquer pessoa física ou empresa, impedidos que são de emitir moeda, gastar mais do que a receita implica dívida eternamente crescente, ainda que se transfira patrimônio para o credor.

\section{A questão da convergência no modelo Sargent \& Wallace}

A partir da equação (1), que descreve o modelo Sargent $\&$ Wallace, pode-se escrever que:

$\mathrm{D} / \mathrm{Y}-\mathrm{D}_{-1} / \mathrm{Y}-\mathrm{r}(\mathrm{D} / \mathrm{Y})=-(\mathrm{T}-\mathrm{GF}) / \mathrm{Y}-\mathrm{dM} / \mathrm{Y}$

ou seja:

$\mathrm{D} / \mathrm{Y}-1 /(1-\mathrm{r}) \mathrm{D}_{-1} / \mathrm{Y}=-1 /(1-\mathrm{r})\{(\mathrm{T}-\mathrm{GF}) / \mathrm{Y}-\mathrm{dM} / \mathrm{Y}\}$

A condição de convergência ao equilíbrio teórico seria então dada por:

$0<1 /(1-\mathrm{r})<1$

\footnotetext{
8 “... as relações de causa e efeito são muito mais complexas do que o simples instrumental da contabilidade nacional pode revelar" (Simonsen \& Cysne, 1989, p. 130).

${ }^{9} \mathrm{Em}$ termos matemáticos, a convergência de uma variável X em direção ao seu ponto de equilíbrio fica assegurada quando o coeficiente de $\mathrm{X}_{-1}$ normalizado é, em módulo, menor do que a unidade. Porém, quando este coeficiente é negativo, a variável $\mathrm{X}$ assume alternadamente valores positivos e negativos, $\mathrm{O}$ que não tem sentido neste particular contexto da economia.

${ }^{10}$ Giambiagi \& Além (1999, pp. 164 e 167) e Dornbusch \& Fischer (1990, p. 614).
} 
Portanto, também no modelo Sargent \& Wallace, a condição matemática de estabilidade do equilíbrio depende da taxa de juros nominal, que deveria estar no intervalo $(-1,0)$, ou seja, ser negativa. Todavia, neste modelo não se analisa a solução complementar da tendência em direção ao equilíbrio.

Pastore (1995) constitui uma exceção, pois busca avaliar a condição de convergência, se bem que seguindo um procedimento diferente. Embora a equação (2) seja derivada da (1), Pastore (1995) considera a (2)11 como sendo uma equação diferencial original, e deduz a sua solução geral (nota de rodapé da p. 5). Esta solução geral resulta da diferenciação e posterior integração da equação (1), mas é diferente da equação (1), e tem duas partes. Na primeira, a condição de convergência da dívida pública para o equilíbrio expresso por (5) é que a taxa exógena de crescimento do PIB seja maior do que a taxa de juros. ${ }^{12} \mathrm{Na}$ segunda, Pastore (1995, p. 5), admitindo que a taxa de juros pode ser maior do que a taxa de crescimento, conclui que a dívida não seguirá uma trajetória explosiva se o superávit primário for aumentado sempre que a dívida crescer.

A busca pelo superávit primário requerido para pagar os juros da dívida pública passou então a monopolizar a questão. Ilustrando, Goldfajn (2002) usa uma fórmula semelhante à desenvolvida por Giambiagi \& Além (1999, p. 167), assume a não emissão de moeda e chega à conclusão de que a dívida, como proporção do PIB, declinaria nos anos seguintes, num quadro construído à época "Sob hipóteses razoáveis e mesmo conservadoras" [...] (p. 24). O texto de Goldfajn (2002) sugere que há apenas duas convicções que dominam a discussão sobre o endividamento público. Em primeiro lugar, apesar da dívida pública seguir uma trajetória explosiva, há confiança em que um dia a solução de equilíbrio será observada. Em segundo lugar, confia-se em que os instrumentos da política econômica podem providenciar esta solução.

Indo adiante, Giambiagi (2005, pp. 10) recomenda, ao governo que assumir em 2007, a fixação de um limite para os gastos fiscais, como proporção do PIB. Entretanto, se este limite for tal que ainda exista déficit nominal, a tendência da relação dívida pública/PIB continuará explosiva.

O pressuposto da natureza exógena do PIB e da sua taxa de crescimento pode inibir outras conclusões de outro modo permitidas pelo modelo. De fato, o modelo de endividamento público poderia ser ampliado, admitindo-se que o PIB e a receita tributária sejam variáveis endógenas, de modo que o valor final arrecadado dependa não só das alíquotas dos tributos, mas também do nível de atividade da economia. Este é o tema do próximo tópico.

\footnotetext{
${ }^{11}$ Com senhoriagem.

${ }^{12}$ Portanto, se a taxa de juros pudesse ser negativa, ainda que o PIB não crescesse a convergência estaria assegurada.
} 


\section{Investimento social e endividamento}

Admita-se que o PIB e, portanto, a receita tributária T, sejam variáveis endógenas, e que se possa descrever $T$ pela equação:

$$
\mathrm{T}=\beta_{0}+\beta_{1} \mathrm{GF}-\beta_{2} \mathrm{D}+\beta_{3} \mathrm{OV}
$$

onde os símbolos são os usuais, OV refere-se a outras variáveis exógenas omitidas e $\beta_{2}$ mede o grau de associação entre a dívida e a receita tributária. A idéia é que uma dívida maior está ligada a uma taxa de juros maior, a qual implica uma renda menor e, portanto, uma receita de impostos também menor. Por isso, espera-se que a derivada de $\mathrm{T}$ em relação a $\mathrm{D}$ seja negativa, ou seja, que $\beta_{2}$ seja positivo.

Assumindo que não haja emissão de moeda e que a dívida seja independente da política monetária, o endividamento é contabilmente descrito por:

$$
\mathrm{D}=\mathrm{D}_{-1}+\mathrm{GJ}-\mathrm{T}+\mathrm{GF}
$$

Substituindo a receita tributária nesta expressão, e o gasto com juros pelo produto da taxa de juros pelo montante da dívida pública no final do período anterior, a expressão contábil do estoque absoluto da dívida pública passa a ser uma equação de diferenças finitas com a forma:

$$
\mathrm{D}=\mathrm{D}_{-1}+\mathrm{r} \mathrm{D}_{-1}-\beta_{0}-\beta_{1} \mathrm{GF}+\beta_{2} \mathrm{D}-\beta_{3} \mathrm{OV}+\mathrm{GF}
$$

Colecionando termos, obtém-se a expressão matemática do comportamento temporal da dívida pública:

$$
\left(1-\beta_{2}\right) \mathrm{D}-(1+\mathrm{r}) \mathrm{D}_{-1}=-\beta_{0}+\left(1-\beta_{1}\right) \mathrm{GF}-\beta_{3} \mathrm{OV}
$$

A solução particular desta equação de diferenças finitas, na hipotética situação em que a dívida pública estivesse em equilíbrio, é dada por:

$$
\mathrm{D}=\left[-1 /\left(\beta_{2}+\mathrm{r}\right)\right]\left[-\beta_{0}+\left(1-\beta_{1}\right) \mathrm{GF}-\beta_{3} \mathrm{OV}\right]
$$

Trata-se de uma solução complexa, que depende parcialmente de parâmetros e variáveis exógenas fora do controle dos executores da política econômica. Por outro lado, a solução complementar é dada por:

$$
\mathrm{D}-\left[(1+\mathrm{r}) /\left(1-\beta_{2}\right)\right] \mathrm{D}_{-1}=0,
$$

A condição para que a dívida pública seja convergente à sua solução de equilíbrio é dada pelas desigualdades:

$0<\left[(1+\mathrm{r}) /\left(1-\beta_{2}\right)\right]<1$

Por um lado, tem-se que:

$(1+\mathrm{r}) /\left(1-\beta_{2}\right)<1$

o que conduz ao primeiro requisito:

$\mathrm{r}<-\beta_{2}$ ou $\beta_{2}<-\mathrm{r}$ 
Do outro lado da desigualdade têm-se duas possibilidades:

a) $(1+r)>0$ e, simultaneamente, $\left(1-\beta_{2}\right)>0$. Neste caso, $r>-1$ e, simultaneamente, $-\beta_{2}>-1$. Combinando com o primeiro requisito, a condição geral de convergência é satisfeita quando $-\beta_{2}>r>-1$.

b) $(1+\mathrm{r})<0$ e, simultaneamente, $\left(1-\beta_{2}\right)<0$. Neste caso, $\mathrm{r}<-1$ e, simultaneamente, $-\beta_{2}<-1$. Combinando com o primeiro requisito, a condição geral de convergência é satisfeita quando $\mathrm{r}<-\beta_{2}<-1$.

Assim, se $\beta_{2}$ for positivo, a condição de convergência implica que a taxa de juros teria necessariamente que ser negativa. Alternativamente, sendo a taxa de juros positiva, para que o equilíbrio fosse estável, um crescimento da dívida teria que estar associado a um aumento da receita tributária, isto é, $\beta_{2}$ teria que ser negativo.

Do ponto de vista econômico privado, esta condição faz sentido. Em situações normais, uma empresa capta recursos para financiar um investimento desde que este seja justificado pelo fato do investimento propiciar um valor presente líquido positivo. Para tanto, $\beta_{2}$ deve ser negativo. De fato, a teoria econômica recomenda o endividamento apenas quando este está associado ao crescimento da receita.

Mutatis mutandis, para que a dívida pública pudesse tender a um equilíbrio estável, seria necessário que os novos recursos financeiros emprestados pelo governo fossem aplicados de modo a gerar receita tributária extra para pagar os respectivos juros. Contudo, ainda que não se faça política monetária com dívida pública, o gasto do governo nos investimentos sociais que lhe são característicos não permite esta performance..$^{13}$

Conclui-se, então, que não há, matematicamente, um ponto de equilíbrio estável para a dívida pública, ou seja, a partir de um ponto fora do equilíbrio, a trajetória temporal da dívida é sempre explosiva. Assim, a condição necessária para que a dívida pública não siga uma trajetória explosiva é que não exista déficit público, isto é, que não exista razão para se fazer dívida pública.

\section{A inconsistência teórica do endividamento público}

A idéia matemática é que o processo de realimentação da dívida pública, que depende da taxa de juros, deve ser decrescente para que, a partir de um nível qualquer de desequilíbrio deficitário causado por um aumento definitivo do fluxo de gastos, a dívida pública cresça em montantes decrescentes até parar de crescer. Daí a dedução matemática de que, para que a trajetória da dívida pública seja convergente ao equilíbrio, ou a taxa de juros relevante é negativa ou o governo realiza investimentos sociais rentáveis, hipóteses para as quais não há suporte teórico ou empírico. Sendo então a instabilidade imanente à dívida pública, há razão

\footnotetext{
${ }^{13} \mathrm{Ou}$ seja, em condições normais espera-se que o produto do multiplicador keynesiano pela carga tributária seja menor do que a unidade. De outro modo, o setor privado estaria investindo no lugar do governo.
} 
para não se rejeitar a tese de que qualquer modelo de endividamento público seja teoricamente inconsistente.

A insistência no endividamento leva a uma busca incessante do equilíbrio por meio de medidas exógenas, sendo este o motivo pelo qual o governo criou um aparato legal para intervir na economia visando à obtenção do superávit primário teoricamente requerido. Talvez a Lei de Responsabilidade Fiscal seja a principal peça deste aparato legal. Todavia, ao admitir um superávit primário insuficiente para o pagamento de juros, esta lei pode mudar o patamar teórico da dívida pública, mas é incapaz de fazer com que a dívida pública existente passe a seguir uma trajetória na direção deste novo patamar. Isto significa que, ao elaborar um orçamento no qual o superávit primário seja inferior ao teoricamente requerido para zerar a necessidade de financiamento do setor público com títulos da dívida pública, o governo federal assume o duplo compromisso de emitir moeda para pagar seus gastos e de emitir títulos.

Por outro lado, na hipotética captação de recursos financeiros a uma taxa de juros negativa, o governo emitiria títulos, teoricamente remunerados ou não, para o mercado financeiro e depois resgataria estes títulos por um valor menor que o da emissão. O mercado financeiro estaria então, como sempre faz, emitindo moeda, mas doando parte dela ao governo. O mercado financeiro, contudo, não estaria disposto a emprestar dinheiro para receber menos no vencimento, ou deixar de levar a resgate parte dos títulos públicos, e nem doar moeda diretamente ao governo. Esta seria uma situação evidentemente forçada, exigindo uma contrapartida significativa por parte do governo, além de um aparato legal específico nos moldes adotados quando da elaboração e implantação da Lei de Responsabilidade Fiscal.

Alternativamente, o governo poderia captar recursos financeiros diretamente do público. Ilustrando, o governo poderia expandir os gastos fiscais, causar um déficit de 100, emitir 100 em títulos diretamente para o público, mas arrecadar menos do que 100 na forma de tributos. Neste caso, o governo emitiria $100 \mathrm{em}$ títulos da dívida pública, nominalmente remunerados ou não, mas só aceitaria receber menos do que 100 no pagamento dos tributos, suponha-se 80 . Os outros 20 ficariam em poder do público ad eternum. Em outros termos, o governo estaria emitindo moeda. ${ }^{14}$ Este é o tema do próximo tópico.

\section{MONETIZAÇÃO DO DÉFICIT PÚBLICO}

Teoricamente, o estoque de moeda emitida para financiar totalmente o déficit público pode tender a um ponto de equilíbrio estável. Assim, um déficit público ocorrido num certo período leva à emissão de um certo volume finito de moeda. Por natureza, este déficit público está, ao mesmo tempo, associado a uma mudança de patamar de preços, mas não necessariamente à sua evolução constante e

\footnotetext{
${ }^{14}$ A este respeito, ver Wray (1998, p. 9) e Willcox (2006, p. 23).
} 
descontrolada. Surge desta forma uma relação de equilíbrio entre o nível de preços e o estoque de moeda.

Imagine-se um país onde o governo seja impedido de fazer dívida diretamente no mercado financeiro interno ou externo. Imagine-se ainda que a lei autorize e obrigue o Banco Central a emitir um certo volume de moeda para o Tesouro Nacional, a juro zero. ${ }^{15}$ Neste caso, o gasto do governo com juros será nulo e o Banco Central não poderá fazer política monetária colocando e resgatando títulos da dívida pública no mercado aberto.

Em conseqüência, o saldo da base monetária aumentará de forma definitiva quando houver déficit fiscal ou superávit em transações correntes, e reduzirá definitivamente nos casos contrários. Considerando que estes fatores condicionantes da base monetária estão associados a operações do lado real da economia, podese denominar a moeda assim criada ou destruída de "moeda primária" (Lima, 2006).

Se todo o déficit público fosse pago com emissão de moeda primária, sem endividamento do governo, o saldo das emissões e retiradas desta moeda seria descrito pela identidade contábil:

$$
\mathrm{M}=\mathrm{M}_{-1}-(\mathrm{T}-\mathrm{GF})+\mathrm{STC}
$$

onde $\mathrm{M}$ é o estoque de moeda primária ao final do período presente, $\mathrm{M}_{-1}$ é o estoque de moeda primária ao final do período imediatamente anterior, $\mathrm{T}$ é a receita tributária e STC é o superávit em transações correntes. Em relação à base monetária, (T - GF) representa as operações do Tesouro Nacional, enquanto STC corresponde às operações do setor externo.

Admita-se que o PIB esteja associado à emissão de moeda primária, sob o argumento de que esta emissão decorre de uma política fiscal expansionista. Admitase também que a arrecadação de impostos T seja função do PIB. Assim, a receita tributária também estará associada à emissão de moeda primária, por exemplo da seguinte forma:

$$
\mathrm{T}=\alpha_{0}+\alpha_{1} \mathrm{M}+\alpha_{2} \mathrm{OV}
$$

O sinal esperado do coeficiente $\alpha_{1}$ é positivo. Substituindo a receita tributária T na identidade contábil do estoque de moeda, ela se transforma em uma equação de diferenças finitas que descreve o comportamento no tempo do estoque de moeda primária: ${ }^{16}$

$$
\mathrm{M}=\mathrm{M}_{-1}-\alpha_{0}-\alpha_{1} \mathrm{M}-\alpha_{2} \mathrm{OV}+\mathrm{GF}
$$

\footnotetext{
${ }^{15}$ Um projeto de lei neste sentido, aplicável aos estados e municípios, foi apresentado ao Congresso americano em abril de 1999 (Wray, 2001).

${ }^{16}$ Como STC é uma variável endógena, ela é função do conjunto de variáveis autônomas e exógenas que explicam M. Portanto, para evitar a combinação linear, ela é eliminada da equação de $\mathrm{M}$ a partir deste ponto.
} 
Colecionando termos e reordenando, tem-se:

$$
\left(1+\alpha_{1}\right) \mathrm{M}-\mathrm{M}_{-1}=-\alpha_{0}+\mathrm{GF}-\alpha_{2} \mathrm{OV}
$$

A solução particular, ou o equilíbrio do estoque de moeda primária, é dada por:

$$
M^{*}=\left(1 / \alpha_{1}\right)\left[-\alpha_{0}+\mathrm{GF}-\alpha_{2} \mathrm{OV}\right]
$$

Este ponto de equilíbrio decorre, pois, dos gastos fiscais e dos níveis de outras variáveis autônomas e exógenas à economia nacional. Como sempre, o estoque de moeda é, em parte, uma conseqüência da política fiscal. Quando, tudo o mais constante, no orçamento aprovado pelo Congresso e executado pelo governo, os gastos fiscais são maiores do que a receita tributária, o déficit resultante será imediatamente incorporado ao estoque de moeda primária.

Por outro lado, a solução complementar, ou seja, a condição de convergência do estoque de moeda primária em direção ao ponto de equilíbrio é:

$$
0<\left[1 /\left(1+\alpha_{1}\right)\right]<1
$$

As soluções são $\alpha_{1}$ positivo $\left(\alpha_{1}>0\right)$ e, simultaneamente, maior do que a unidade com sinal negativo $\left(\alpha_{1}>-1\right)$. Portanto, a condição necessária para que haja convergência do estoque de moeda primária a uma situação de equilíbrio estável é que $\alpha_{1}$ seja positivo. Esta condição corresponde a uma correlação positiva entre a receita tributária e o estoque de moeda primária, ou entre esta receita e o PIB, entre o PIB e os gastos fiscais e entre estes gastos e o estoque de moeda primária. Para que esta correlação entre receita e moeda não fosse positiva, seria necessária a ocorrência de pelo menos uma entre três possibilidades.

Primeiro, que o aumento dos gastos fiscais, ceteris paribus, não expandisse a base monetária. Segundo, que a expansão dos gastos fiscais, ceteris paribus, não estivesse associada a variações positivas do PIB, ainda que apenas em decorrência da elevação dos preços, ou então que a política fiscal causasse recessão. Por último, que, ceteris paribus as alíquotas dos impostos, a receita tributária não aumentasse quando houvesse crescimento econômico. Como falta amparo teórico a estas três possibilidades, não há razões para supor que não exista uma correlação positiva entre a receita tributária e o estoque de moeda primária.

É então possível que se elaborem orçamentos com previsão de déficit público, em especial se os projetos de investimentos nele incluídos demonstrarem que, estando a economia abaixo do pleno emprego, haverá aumento do PIB e da receita tributária. Após a aprovação do Congresso, o sistema econômico poderá levar a uma solução de equilíbrio estável para o estoque de moeda primária. Este ponto de equilíbrio, dados os níveis das variáveis autônomas e exógenas, seria função direta dos gastos fiscais. Quando o gasto fiscal assume um novo valor, ceteris paribus as outras variáveis OV, o saldo de equilíbrio da moeda primária muda de patamar. Após algum tempo decorrido, este patamar será atingido e, se não houver mais variação exógena de GF ou OV, o saldo da moeda primária permanecerá fixo e estável, ou seja, sem tendência a mudar. 
Em termos dinâmicos, a cada vez que o gasto fiscal aumentar, haverá um novo e maior saldo da moeda primária de equilíbrio estável. Ceteris paribus as outras variáveis autônomas e exógenas, o saldo da moeda primária varia com os gastos fiscais, na mesma direção, e permanece constante se o fluxo de gastos fiscais não varia. Assim, num processo de crescimento do PIB conduzido por uma política keynesiana, moderada e financiada a juro zero por expansão de base monetária causada por operações do Tesouro Nacional, ${ }^{17}$ o estoque de moeda primária cresceria de forma moderada e constante, sem tendência a explodir. Ou seja, haveria crescimento econômico e a inflação estaria limitada e sob controle.

Por coincidência, esta conclusão está de acordo com a proposta monetarista de Milton Friedman, ${ }^{18}$ sustentada com base na teoria quantitativa da moeda. Segundo ele, a política monetária não deveria ser discricionária, mas sim seguir regras de longo prazo e manter a oferta de moeda crescendo a uma taxa moderada, constantemente. Neste caso, os preços também aumentariam, junto com o PIB real, a uma taxa constante. Vista desta ótica monetarista, a emissão de moeda também estaria associada ao crescimento econômico e à inflação sob controle.

A emissão de moeda associada ao déficit primário pode ser vista como uma captação de recursos financeiros por parte do governo por meio da emissão de títulos não remunerados. Esta captação seguiria um procedimento em tudo semelhante ao da suposta rolagem automática da dívida sem emissão de moeda para pagar os juros. Estas são duas hipóteses radicais inaceitáveis pelos bancos privados, porque eles não podem reter um estoque crescente e não remunerado de títulos de qualquer dívida, privada ou pública.

O caminho mais simples e viável é a emissão de moeda para o público, sob controle do orçamento público federal. Neste caso, o governo federal faria seus gastos fiscais em excesso da receita e o Banco Central, ao honrar as ordens de pagamento do Tesouro Nacional, emitiria moeda primária e expandiria a base monetária. Os recursos assim captados teriam sido investidos na sociedade, gerando um aumento do PIB e, por isso, da arrecadação tributária, o que faria cessar a emissão de moeda em algum momento futuro.

O fato de, inicialmente, a receita tributária ser menor do que o gasto fiscal significa que o governo estaria emitindo um volume maior de moeda do que ele aceitaria em pagamento dos impostos. Em conseqüência, parte da moeda primária emitida ficaria em poder do público, sem remuneração. Esta moeda seria usada nas transações entre agentes privados, e o estoque maior atenderia às necessidades de giro de uma economia expandida.

Estando ou não a economia em pleno emprego, o déficit público financiado totalmente com emissão de moeda causa uma mudança de patamar dos preços, mas não uma inflação sem controle. Assim, tanto para o PIB como também no

\footnotetext{
${ }^{17}$ A proposta de Morrison (2006, p. 51) é um "Keynes sem dívida pública”.

${ }^{18}$ A famosa proposta de Friedman pode ser encontrada, por exemplo, em Dornbusch \& Fischer, 1990, p. 682, e em Mankiw, 2004, p. 270.
} 
caso da receita tributária, uma parte do aumento seria real, por expandir a produção, ou seja, a base tributária. Por sua vez, a outra parte seria nominal, isto é, dever-se-ia à mudança de patamar dos preços.

Como, nesta visão teórica, a moeda primária é emitida por conta de um déficit orçamentário, poder-se-ia dizer que é a decisão autônoma do poder executivo federal de expandir o gasto fiscal que causa o aumento dos preços, e não uma medida de ordem monetária do Banco Central. Nesta perspectiva, o que causa um aumento de produção e preços é um gasto fiscal maior e não apenas um saldo mais elevado de moeda, é o fluxo e não o estoque. Por outro lado, a taxa de inflação dependeria do déficit público e, portanto, poderia ser planejada, e estaria sob controle do governo e do poder Legislativo durante a execução do orçamento público federal.

Estas conclusões não podem ser, contudo, usadas para sugerir que o governo emita moeda para emprestar ao público, a taxas favorecidas ou não. Em princípio, emitir moeda é uma questão de crédito e não parece competir ao governo a análise de cadastros de empresas e pessoas do setor privado, e muito menos daquelas não distanciadas dos membros do próprio governo. Também não dão suporte à sugestão de Wray $(1998$, p. 9), no sentido de que o governo pode oferecer títulos no mercado financeiro, e tampouco justificam a colocação de Willcox (2006, p. 23), que considera a política monetária viável.

\section{CONCLUSÕES}

Para qualquer endividamento público, com ou sem política monetária, com ou sem taxas de juros acima do mercado, se a receita total não for suficiente para cobrir os gastos fiscais e o gasto com juros, a dívida pública seguirá um processo explosivo. Por outro lado, para que a dívida pública tenha uma solução de equilíbrio estável, a condição matemática, impossível de ser literalmente atendida, é que a taxa de juros nominal seja negativa. Alternativamente, pode-se dizer que, dada uma taxa positiva de juros, a dívida pública só convergiria para uma situação de equilíbrio estável se os recursos assim captados fossem investidos e criassem receita tributária líquida nova suficiente para pagar os respectivos juros.

Nos termos do modelo Sargent \& Wallace, a recomendação mais difundida para impedir que a dívida pública siga uma trajetória explosiva é de natureza contábil. Esta recomendação é a de que seja feito um ajuste fiscal, ou seja, que se imponha um aumento do superávit primário baseado em cortes de gastos fiscais ou na elevação da carga tributária. Alguns autores adicionam a possibilidade de uma senhoriagem controlada. Contudo, se a senhoriagem for administrada pela política monetária, esta certamente influenciaria o nível da própria dívida pública. Seria, assim, violado o pressuposto de independência entre a política monetária e a dívida pública na análise do endividamento público.

Apesar de seus méritos, as recomendações baseadas no modelo Sargent \& Wallace não superam o fato de as condições matemáticas de convergência - a taxa de juros nominal negativa ou o retorno positivo do endividamento - serem fe- 
nômenos que não são parte integrante da estrutura e da política econômica. Uma atenuante sempre lembrada seria a confiança em um possível crescimento do PIB e, portanto, da arrecadação tributária. Contudo, a expansão do PIB, neste caso, se não for exógena e independente das aspirações do governo, dependerá de medidas de política econômica que também causam inflação.

Enquanto não for obtido um superávit primário suficiente para servir a dívida pública, ela seguirá uma trajetória explosiva, mais moeda será emitida e mais medidas exógenas serão tomadas. Se for adotada uma política monetária que implique aumento da dívida pública, esta trajetória será acelerada. Mais ainda, o próprio déficit público, financiado com dívida pública, seguirá esta tendência explosiva. O argumento em defesa desta situação matematicamente divergente, descontrolada e incontrolável, é a de que este é o custo a pagar para não se ter inflação. Nesta linha, a não-inflação é o retorno esperado do investimento social cujo financiamento alimenta a dívida pública. O paradigma que sustenta esta situação diz que a inflação é um resultado certo, e absolutamente indesejável, da emissão de moeda para cobrir déficits primários.

Entretanto, demonstrou-se que a emissão de moeda para financiar o déficit fiscal leva o estoque de moeda primária a convergir para um nível de equilíbrio estável. A validade desta conclusão apóia-se em três hipóteses aderentes à realidade. Primeiro, que os gastos fiscais expandem a base monetária. Segundo, que o aumento dos gastos fiscais sem endividamento público não causa recessão e, terceiro, que o crescimento do PIB provoca um aumento na arrecadação tributária.

Além disso, pagar o gasto fiscal em excesso da receita tributária com emissão de moeda equivale logicamente a emitir títulos da dívida pública com taxa de juros negativa. A condição matemática que torna o endividamento público explosivo e incontrolável é a mesma que garante que o estoque de moeda emitida para pagar o déficit primário converge para um nível de equilíbrio estável. Assim, o efeito inflacionário de um déficit fiscal do governo desapareceria depois de transcorrido o período de tempo necessário para que, percorrida uma trajetória convergente, os preços atingissem um novo patamar. Para cada montante de gasto fiscal estaria associado um estoque de moeda em equilíbrio estável, de forma que, se os gastos fiscais não variarem, o estoque de moeda também não se alterará.

Apoiado nesta perspectiva teórica, o governo poderia adotar uma política fiscal expansionista, planejada de acordo com o orçamento público e com a capacidade física de expansão do PIB real, de modo que houvesse crescimento econômico e a inflação assumisse um nível controlado, convergente e estável. Em conseqüência da expansão dos gastos fiscais, o aumento da base monetária estaria canalizando para os bancos privados novos depósitos em conta corrente. Estes novos depósitos poderiam ser multiplicados e aplicados na produção, que estaria então em processo de expansão. Ao deixar de tomar recursos no mercado financeiro, o governo deixaria de competir com o setor privado na demanda de capital financeiro e passaria a aportar capital para os bancos emprestarem ao próprio setor privado.

Em resumo, o endividamento público, sem que haja criação de receita tributária extra suficiente para pagar os juros, gera um processo explosivo do estoque da dívi- 
da pública e, portanto, do gasto do governo com juros. Por conseguinte, o superávit primário e o corte de investimentos sociais requeridos são cada vez maiores e há uma sempre crescente e descontrolada emissão de moeda. Este processo inviabiliza o pretendido controle da inflação. Em consequiência, o endividamento público leva à instabilidade dos preços e, ao final, da própria economia como um todo.

A essência do que é econômico é o retorno de um investimento. É a perspectiva de uma taxa de retorno acima da taxa de juros que justifica o investimento, assim autorizando a alocação de recursos financeiros próprios ou obtidos por empréstimo. Esta não é, certamente, a perspectiva que se pode associar ao endividamento público, de forma que, ao endividar-se, o governo desperdiça recursos da sociedade e promove uma concentração patrimonial. A principal conclusão desta análise é que, tendo como referência uma política econômica de crescimento do PIB e da oferta de emprego, há suporte para se considerar que a alternativa de financiar a expansão os gastos fiscais do governo com emissão de moeda é não apenas superior à do endividamento público, mas a única que se pode recomendar com base na teoria econômica.

\section{REFERÊNCIAS BIBLIOGRÁFICAS}

CHIANG, A. "Matemática para Economistas". São Paulo: Editora McGraw-Hill do Brasil e Editora da Universidade de São Paulo, 1982.

DORNBUSCH, R. \& FISCHER, S. "Macroeconomics", McGraw-Hill, 5ª edição, 1990.

GIAMBIAGI, F. “Uma Agenda Fiscal para 2007-10”. Brasília: IPEA — Instituto de Pesquisas Econômicas, Texto de Discussão \#1123, outubro de 2005.

GIAMBIAGI, F. \& ALÉM, A. C. "Finanças Públicas: Teoria e Prática no Brasil”. Rio de Janeiro: Editora Campus, 1999.

GOLDFAJN, I. “Há Razões para Duvidar de Que a Dívida Pública no Brasil é Sustentável?”. Notas Técnicas do Banco Central do Brasil, n 25, Julho de 2002.

MARTONE, C. L. "Moeda, Dívida Pública e Inflação", in LOPES L. M. \& VASCONCELOS M. A. S. (.) "Manual de Macroeconomia”. São Paulo: Editora Atlas, 2a edição, 2000.

LIMA, G. "Política Monetária e Dívida Pública”, Revista da FAE, vol. 9, nº 1, pp. 71-81, jan.-jun. de 2006.

MORRISON, R. “Keynes Without Debt”. Post-autistic Economics Review (www.paecon.net), n 39, outubro de 2006.

PASTORE, A. C. "Déficit Público e a Sustentabilidade do Crescimento das Dívidas Interna e Externa, Senhoriagem e Inflação: uma Análise do Regime Monetário Brasileiro”. Revista de Econometria, vol. 14, n 2, pp. 177-234, 1995.

ROSSI, J. W. “A Dívida Pública no Brasil e a Aritmética da Instabilidade”. Pesquisa e Planejamento Econômico, vol. 17, n. 2, agosto de 1987.

SIMONSEN, M. H. \& CYSNE, R. P. “Macroeconomia”. Rio de Janeiro: Ao Livro Técnico Editora, 1989.

WRAY, L. R. “Modern Money”, Working Paper \#252, The Jerome Levy Economics Institute of Bard College (www.levy.org), Setembro de 1998.

WRAY, L. R. "Financing State and Local Government Infrastructure Investment". Special Report 01/03, CFEPS - Center for Full Employment and Price Stability, University of Missouri - Kansas City, novembro de 2001.

WILLCOX, L. D. "Endividamento forçado, Big Government e a implausibilidade de crise no capitalismo: um exercício a partir de um modelo de consistência entre fluxos e estoques". http://www. desempregozero.org.br/ensaios_teoricos/ index.php, acesso em 14 de janeiro de 2006. 